\title{
Efficacy of Tramadol, Low Dose Ketamine and Ondansetron in the Management of Intra-Operative Shivering After Sub Arachnoid Block
}

\author{
Md. Aminul Hasanat ${ }^{1}$, MM Abdul Wadud ${ }^{2}$, Abdul Hye ${ }^{3}$, AKM Akhtaruzzaman ${ }^{4}$, \\ Lutful Kabir ${ }^{5}$, Md. Mahfuzur Rahman ${ }^{6}$, Mohammed Ashraful Haque \\ ${ }^{1}$ Assistant Professor, Department of Anesthesiology, National Institute of Neurosciences \& Hospital, Dhaka, Bangladesh; \\ ${ }^{2}$ Anaesthesia Specialist, Khoula Hospital, Muscat, Oman; ${ }^{3}$ Professor, Department of Anesthesiology, Bangabandhu \\ Sheikh Mujib Medical University, Dhaka, Bangladesh; ${ }^{4}$ Professor, Department of Neuro-Anesthesiology, \\ Bangabandhu Sheikh Mujib Medical University, Dhaka, Bangladesh; ${ }^{5}$ Assistant Professor, Department of \\ Anesthesiology, National Institute of Cardiovascular Diseases \& Hospital, Dhaka, Bangladesh; ${ }^{6}$ Assistant \\ Professor, Department of Neurotrauma, National Institute of Neurosciences \& Hospital, Dhaka, \\ Bangladesh; ${ }^{7}$ Assistant Professor, Department of Neurosurgery, National Institute of \\ Neurosciences \& Hospital, Dhaka, Bangladesh
}

[Received: 21 August 2017; Revised: 6 October 2017; Accepted: 11 December 2017; Published: 1 January 2018]

\begin{abstract}
Background: Shivering is a common problem faced by an anesthesiologist during per-operative period as well as in post-operative period. Objective: The present study was designed to observe the efficacy of tramadol, low dose ketamine and ondansetron in the management of intra-operative shivering after sub arachnoid block. Methodology: This single center, parallel, double blind randomized control trialwas conducted in the Department of Anaesthesia, Analgesia and Intensive Care Medicine at Bangabandhu Sheikh Mujib Medical University, Dhaka, Bangladesh from July 2007 to June 2009 for a period of two (02) years.Patients undergoing surgery with Sub Arachnoid Block, patients with age range from 18 to 60 years, patients from both sexes and ASA class I and class II were selected as study population.After recruitment each subject was allowed to draw one card and grouped accordingly. Group T: Shivering was treated with tramadol. Group K: Low dose ketamine was used to manage shivering. Group 0: Ondansetron was injected for shivering. The patients was also monitored for complications like nausea, vomiting and respiratory depression (defined as respiratory rate $<8 /$ minute). Time taken for cessation of shivering was noted for all groups and all patients were watched for recurrence of shivering. Result: A total of 90 (ninety) patients were enrolled in this study of whom thirty (30) patients were enclosed in each group. Among thirty patients in each group. Group T was effective in $27(90 \%)$ patients, group K was effective in $21(70 \%)$ patients and group $\mathrm{O}$ in $20(66.7 \%)$ patients with a $\mathrm{p}$ value of 0.075 . Statistically, though it is not significant but according to the consideration of percentage, Group $\mathrm{T}$ is superior to other two groups. Again recurrence of shivering occurred in one patient in Gr.-T, eight (08) person in Gr.-K and three (03) patient in group Gr.-O indicating a $\mathrm{p}$ value of 0.024 . This equation reflects the lowest statistically significant recurrence of shivering in Group $\mathrm{T}$ than others.Out of thirty patients in each group, nausea or vomiting occurred only in 3 patients of $\mathrm{T}$ group (10\%) respiratory depression occurred in 10 patients $(33.3 \%)$ of $\mathrm{K}$ group only. Conclusion: The efficacy of tramadol is a better option than low dose ketamine and ondansetron in the management of intra-operative shivering after sub arachnoid block. [Journal of National Institute of Neurosciences Bangladesh, 2018;4(1): 45-50]
\end{abstract}

Keywords: Efficacy; tramadol; ketamine; ondansetron; management; intra-operative shivering; sub arachnoid block

Correspondence: Dr. Md. AminulHasnat, Assistant Professor, Department of Anesthesiology, National Institute of Neurosciences \& Hospital, Sher-E-Bangla Nagar, Agargaon, Dhaka-1207, Bangladesh; Email:hasanat.bablu@gmail.com; Cell no.: +8801711820138 Conflict of Interest: The authors declare that they have no competing interest.

Contributions to Authors': Hasanat MA, Wadud MMA, Hye A were involved in the procedure and collect the data. Akhtaruzzaman AKM, Kabir L were involved the reporting, data analysis and writing the manuscript. Rahman MM \& Haque MA were revised the manuscript. All the authors have read and approved the final version of the manuscript.

Funding: This research project was not funded by any group or any institute on.

How to cite this article: Hasnat MA, Wadud MMA, Hye A, Akhtaruzzaman AKM, Kabir L, Rahman MM, Haque MA. Efficacy of Tramadol, Low Dose Ketamine and Ondansetron in the Management of Intra-Operative Shivering After Sub Arachnoid Block. J National Institute of Neurosciences Bangladesh, 2018;4(1): 45-50

Copyright: C2018.Hasnat et al. Published by Journal of National Institute of Neurosciences Bangladesh. This article is published under the Creative Commons CC BY-NC License (https://creativecommons.org/licenses/by-nc/4.0/). This license permits use, distribution and reproduction in any medium, provided the original work is properly cited, and is not used for commercial purposes. 


\section{Introduction}

Shivering is of great importance because of its potential deleterious effect ${ }^{1}$. Although it occurs during both general anaesthesia and regional anesthesia,it is more frequent and troublesome during regional anaesthesia. Around $40-60 \%$ of the patients undergoing regional anaesthesia develop shivering ${ }^{2}$. Apart from the increase risk of incidental trauma, disruption of medical devices, it can interfere with ECG and pulse oxymetry monitoring. Associated increase in minute ventilation and cardiac output may precipitate ventilatory failure in patient with limited reserve of coronary function or myocardial ischanemia ${ }^{3}$. There are two broad methods to control shivering. They are a non-pharmacological and pharmacological intervention. The non-pharmacological process included passive insulation and active cutaneous heating. Passive insulation reduces cutaneous heat loss by 20 to $30 \%$ and varies only slightly depending on insulation fabrics like heating blankets plastic bags, cotton blankets 4 . Electrical resistive circuit heaters include heated' water circuit, forced air warmer and electrical blankets. But there are many problems regarding non-pharmacological method for shivering control.

Effect of tramadol on spinal and nervous system via adrenergic and serotoninergic pathway explains the reduced tendency of respiratory depression. Adverse effect nausea and vomiting is also dose dependent and therefore more likely to appear if the loading dose is high $^{5}$. This can be minimized by exact dose and slow injection. Ondansetron is a serotonin receptor antagonist. Serotonin (5-hydroxytryptamine) is a critical thermoregulatory neurotransmitter and a biological amine that is found in brain and spinal cord. Hence ondansetron causes a generalized thermoregulatory inhibition at the level of hypothalamus where the bulk of thermoregulatory control occurs but it does not affect the shivering threshold ${ }^{6}$. In this respect ondansteron is aprior antishivering agent. Ketamine is a competitive NMDA receptor antagonist that modulate thermoregulation at a number of level by acting on noradrenergic and serotonergic neuron in the locus coeruleus and dorsal raphae nucleus through NMDA receptor at the dorsal horn of the spinal cord and normally modulate ascending. nociceptive transmission. Again, ketamine has several other pharmacologic properties that include opioid agonist which blocks amine uptake in the descending inhibitory monoaminergic pain pathway; it has local anaesthetic action and interacts with muscarinic receptor ${ }^{6}$. Therefore it probably controls shivering by non-shivering thermogenesis either by action on hypothalamus or by adrenergic effect of nor ephenephrine. So in respect of shivering, it is a strong contender. The present study was designed to observe the efficacy of tramadol, low dose ketamine and ondansetron in the management of intra-operative shivering after sub arachnoid block.

\section{Methodology}

Study Settings and Place: This study was designed as single center, parallel, double blind randomized control trial. This study was conducted in the Department of Anaesthesia, Analgesia and Intensive Care Medicine at Bangabandhu Sheikh Mujib Medical University, Dhaka, Bangladesh from July 2007 to June 2009 for a period of two (02) years.

Study population:Patients who were needed either emergency or elective surgery under sub arachnoid block like caesarian section, total abdominal hysterectomy and vaginal hysterectomy which average operation duration was about 1 to 3 hours were included in this study. Patients undergoing surgery with Sub Arachnoid Block, patients with age range from 18 to 60 years, patients from both sexes and ASA class I and class II were selected as study population. Patients with urological endoscopic operation, BMI $>30 \mathrm{kgm} 2, \mathrm{H} / \mathrm{O}$ convulsion and multiple allergy, Administration of blood or blood product, hypertension or CAD or compromised cardiorespiratory condition, Fever, thyroid disease, Diabetes Mellitus, On long term phenothiazines and MAO inhibitors, Any dys-autonomia syndrome were excluded from the study.Demographic 'data including age, sex, weight and type of surgery was recorded for all subjects. Vital sign including pulse rate, systolic blood pressure (Systolic Blood Pressure), diastolic blood pressure (DBF), and temperature was recorded at the time of consent and immediately before spinal anaesthesia.

Randomization and Blinding: A total of 90 cards, 30 in each group was prepared by another person who was blinded for this study. Written informed consent was taken from patients. After recruitment each subject was allowed to draw one card and grouped accordingly.Group T: Shivering was treated with tramadol. Group K: Low dose ketamine was used to manage shivering. Group 0: Ondansetron was injected for shivering.

Allocation and Intervention: With approval from the ethical committee of this institution, written informed consent was obtained from patients. After a preload of $10 \mathrm{ml} / \mathrm{kg}$ Hartmann solution, all Sub Arachnoid Block patient for caesarian section received $2.5 \mathrm{cc}(12.5 \mathrm{mg})$ and other category of Sub Arachnoid Block patient $3.5 \mathrm{cc}(17.5 \mathrm{mg})$ of Bupivacaine heavy as those patients 
need higher block with a longer duration of surgery. Level of sensory block was determined by pin prick and motor loss was estimated by Bromage scale. After beginning of surgery, every patients was observed for shivering and pain by the respective grade and scale at 10 minutes interval.

Follow up and Outcome Measures: Pulse, BP, SP02 were recorded at 3 minutes interval from the monitor display after Sub Arachnoid Block for a duration of 30 minutes and later on at 5 minutes interval. The patients was also monitored for complications like nausea, vomiting and respiratory depression (defined as respiratory rate $<8$ /minute). As soon as shivering found, group $\mathrm{T}$ was received tramadol $1 \mathrm{mg} / \mathrm{kg}$, group $\mathrm{K}$ was received ketamine $\mathrm{HCL} \quad 0.5 \mathrm{mg} / \mathrm{kg}$ and group Oondensetron 8mg IV slowly injected over a period of 2 minutes. Time taken for cessation of shivering was noted for all groups and all patients were watched for recurrence of shivering. If failure of control of shivering occurred with any of the above agent, then the patient was treated with $25 \mathrm{mg}$ pethidine.

Ethical consideration: Prior to the commencement of the study, the thesis protocol was approved by the local ethical committee of Bangabandhu Sheikh Mujib Medical University. The aims and objectives of the study along with its procedure, risks and benefit of the study was explained to the patients in an easily understandable local language and then informed written consent was taken from each patient. It was assured that all information and records would be kept confidential and the procedure would be helpful for both the surgeon and the patients in making rational approach of the case management.

Data analysis: It was analyzed by computer with the help of SPSS win 15 software package. Statistical analysis was done by using appropriate procedure like ANOVA (F) test and Chi-square test. Statistical significance was 0.05 level and confidence limit at $95 \%$.

\section{Results}

A total of 90 (ninety) patients were enrolled in this study of whom thirty (30) patients were enclosed in each group. In this study ninety patients were randomly assigned into three equal groups and thirty in each group. Data of the study were analyzed in the light of comparison between the subject groups namely tramadol $(\mathrm{Gr}\urcorner \mathrm{T})$ group, ketamine $(\mathrm{Gr}-\mathrm{K})$ group and ondansetron $(\mathrm{Gr}-\mathrm{O})$ group.

Demographic characteristics of patients: All results were expressed as mean $\pm \mathrm{SD}$ or in frequencies as applicable. These study groups became statistically matched for age in years $\mathrm{Gr} \neg \mathrm{T}=34.20 \pm 12.82, \mathrm{Gr}-\mathrm{K}=$ $32.97 \pm 11.87$ and $\mathrm{Gr}-\mathrm{O}=35.20 \pm 14.10(\mathrm{P}=0.800)$, body weight in $\mathrm{Kg}$ Gr- $\mathrm{T}=54.67 \pm 11.30, \mathrm{Gr}-\mathrm{K}=$ $54.40 \pm 4.55$ and $\mathrm{Gr}-\mathrm{O}=58.87 \pm 12.67(\mathrm{P}=0.167)$ and duration of operation in minutes $\mathrm{Gr}-\mathrm{T}=64.73 \pm 20.61$, $\mathrm{Gr}-\mathrm{K}=6747 \pm 15.17$, Gr-O $=61.33 \pm 15.25(\mathrm{P}=0.388)$ (Table 1).

Table 1: Age, Weight, Duration of Operation, Amount of Drug by Method

\begin{tabular}{lcccc}
\hline Variables & \multicolumn{3}{c}{ Method use of control shivering } & p value \\
\cline { 2 - 4 } & GroupT & GroupK & GroupO & 0.800 \\
\hline Age (in year) & $34.20 \pm 12.82$ & $32.97 \pm 11.87$ & $35.20 \pm 14.10$ & 0.167 \\
Weight (in kg) & $54.67 \pm 11.30$ & $54.40 \pm 4.55$ & $58.87 \pm 12.67$ & 0.388 \\
Duration of OP & $64.73 \pm 20.61$ & $67.47 \pm 15.17$ & $61.33 \pm 15.25$ & \\
\hline
\end{tabular}

*ANOVA test was done to measure the level of significance. Data was shown as Mean $\pm \mathrm{SD}$; Group-T = Tramadol $1 \mathrm{mg} / \mathrm{kg}$; Group-K

$=$ Ketamine $0.5 \mathrm{mg} / \mathrm{kg}$; Group $-\mathrm{O}=$ Ondansetron $8 \mathrm{mg} ; \mathrm{OP}=$ operation in minute

Table 2: Type of Surgery among the study Population

\begin{tabular}{lcccc}
\hline Type of surgery & \multicolumn{3}{c}{ Method use of control shivering } & p value \\
\cline { 2 - 4 } & GroupT & GroupK & GroupO & $24(80.0)$ \\
\hline Caesarian section & $21(70.0)$ & $20(66.7)$ & $4(13.3)$ & 0.699 \\
Abd. Hyster. & $6(20.0)$ & $5(16.7)$ & $2(6.7)$ & \\
V.hyster. & $3(10.0)$ & $5(16.7)$ &
\end{tabular}

*Chi-square test was done to measure the level of significance. \#Figure within parentheses indicates in percentage; Abd. Hyster.= Abdominal hysterectomy; V. hyster.= Vaginal hysterectomy 
Table 3: Shivering grade among the Study population

\begin{tabular}{lcccc}
\hline Shivering grade & GroupT & GroupK & GroupO & p value \\
\hline At 1 minute & 0.0 & 0.0 & 0.0 & 0.020 \\
After 10 minute & $0.83 \pm 0.91$ & $0.33 \pm 0.55$ & $0.60 \pm 0.50$ & $1.40 \pm 0.72$ \\
After 20 minute & $1.40 \pm 0.97$ & $1.20 \pm 1.03$ & $1.80 \pm 1.03$ & 0.623 \\
After 30 minute & $1.47 \pm 1.33$ & $1.67 \pm 1.42$ & $1.73 \pm 1.28$ & 0.596 \\
After 40 minute & $0.62 \pm 1.08$ & $0.70 \pm 1.09$ & $1.07 \pm 1.36$ & 0.001 \\
After 50 minute & $0.39 \pm 0.86$ & $0.50 \pm 0.97$ & $0.56 \pm 1.09$ & 0.045 \\
After 60 minute & $0.28 \pm 0.75$ & $0.54 \pm 1.07$ & $0.33 \pm 0.82$ & 0.896 \\
After 70 minute & $0.42 \pm 1.00$ & $0.55 \pm 0.93$ & $0.67 \pm 1.03$ & 0.053 \\
After 80 minute & 0.0 & $1.00 \pm 1.10$ & $0.50 \pm 1.00$ & 0.010 \\
After 90 minute & 0.0 & $1.60 \pm 0.89$ & 0.0 & \\
After 100 minute & 0.0 & 0.0 &
\end{tabular}

*ANOVA test was done to measure the -level of significance.

Type of Surgery Done: Three types of surgery were performed in each group, namely caesarian section, abdominal hysterectomy, and vaginal hysterectomy. Number of caesarian section was 21 in T group (70\%), 20 in K group (66.7\%) and 24 in 0 group (80\%). Showing a $\mathrm{p}$ value of 0.699 which indicates no significant difference of the quantity of caesarian section between 3 groups. Beside this, abdominal hysterectomy was done 6 patients (20\%) of T group, 5 patients (16.7\%) of $\mathrm{K}$ group and 4 patients $(13.3 \%)$ of 0 group. Similarly vaginal hysterectomy was performed in 3 patient of $\mathrm{T}$ group (10\%), 5 patients of $\mathrm{K}$ group (16.7\%) and 2 patient $(67 \%)$ of 0 group (Table 2).

Shivering status: At the beginning of the operation, the shivering grade was zero for all groups. At $30^{\text {th }}$ minute of operation, shivering grade of Gr-T group was $1.47 \pm 1.33$, Gr-K group $=1.67 \pm 1.42$ and Gr-O group $=1.80 \pm 1.03,(\mathrm{p}$ $=0.596)$. Near to the end of operation i.e. at $60^{\text {th }}$ minutes, the grading of shivering was $\mathrm{Gr}-\mathrm{T}=0.28 \pm 0.75, \mathrm{Gr}-\mathrm{K}=$ $0.54 \pm 1.07$, Gr-O $=0.56 \pm 1.09$ ( $\mathrm{p}=0.621)$. So therewas no statistically significant difference of shivering between the three groups (Table 3).

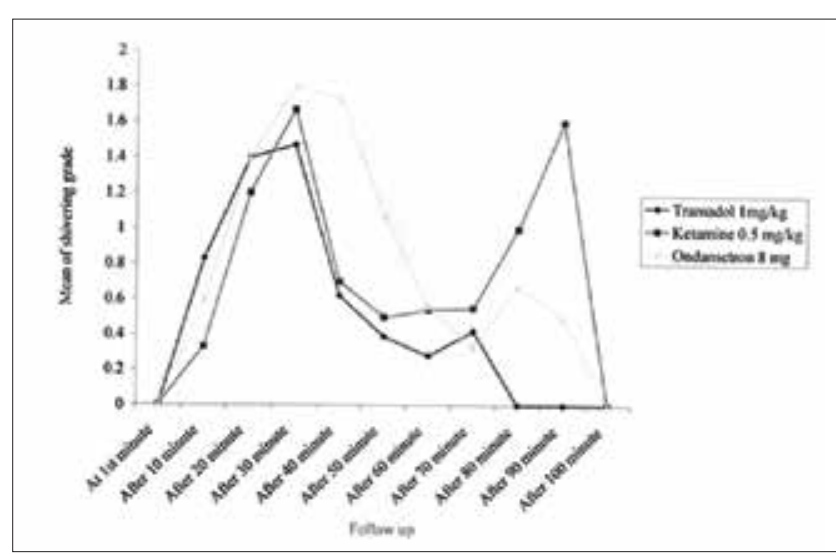

Figure I: Graph showing the Shivering Score
Effectiveness of drugs for shivering control: Among thirty patients in each group. Group $\mathrm{T}$ was effective in 27 patients $(90 \%)$, group $\mathrm{K}$ was effective in 21 patients $(70 \%)$ and group $\mathrm{O}$ in 20 patients $(66.7 \%)$ with a $\mathrm{p}$ value of 0.075 . Statistically, though it is not significant but according to the consideration of percentage, Group $\mathrm{T}$ is superior to other two groups. Again recurrence of shivering occurred in one patient in Gr.-T, eight (08) person in Gr.-K and three (03) patient in group Gr.-O indicating a $p$ value of 0.024 . This equation reflects the lowest statistically significant recurrence of shivering in Group T than others (Table 4).

Table 4: Effectiveness of drugs used in the treatment of shivering (Tramadol Img/kg, Ketamine $0.5 \mathrm{mg} / \mathrm{kg}$ and Ondansetron $8 \mathrm{mg}$ )

\begin{tabular}{lcccc}
\hline Shivering & GroupT & GroupK & GroupO & p value* $^{*}$ \\
\hline Effective & $27(90.0) \#$ & $21(70.0)$ & $20(66.7)$ & 0.075 \\
Recurrence & $1(3.3)$ & $8(26.7)$ & $3(10.0)$ & 0.024 \\
\hline
\end{tabular}

*Chi-square test was done to measure the level of significance. \#Figure within parentheses indicates in percentage.

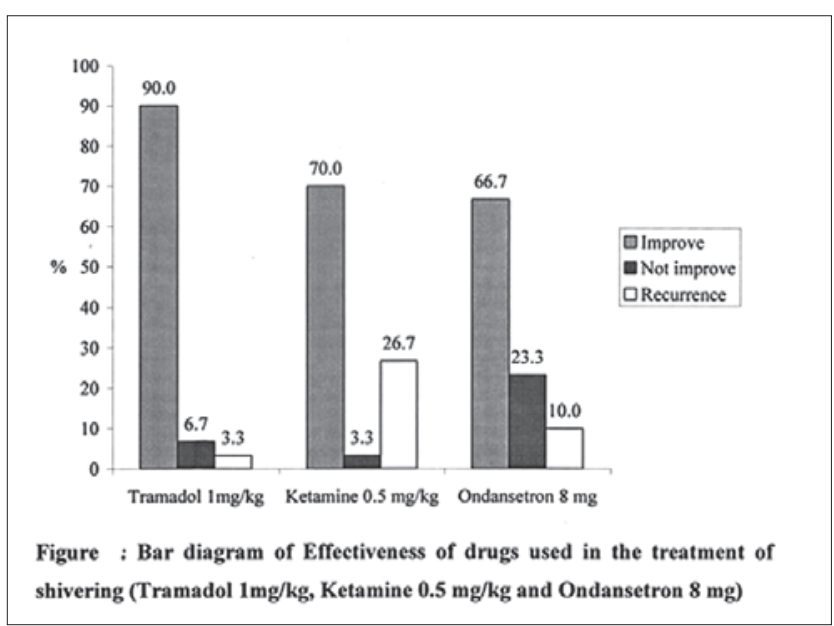


Complications: Out of thirty patients in each group, nausea or vomiting occurred only in 3 patients of $\mathrm{T}$ group $(10 \%)$ respiratory depression occurred in 10 patients (33.3\%) of K group only (Table 5).

Table 5: Complicationsof drugs used in the treatment of shivering (Tramadol Img/kg, Ketamine $0.5 \mathrm{mg} / \mathrm{kg}$ and Ondansetron $8 \mathrm{mg}$ )

\begin{tabular}{lcccc}
\hline Complications & GroupT & GroupK & GroupO & p value \\
\hline Nausea or Vomiting & $3(10.0)$ & $0(.0)$ & $0(.0)$ & $3(3.3)$ \\
Respiratorydepression & $0(0.0)$ & $10(33.3)$ & $0(.0)$ & $10(11.0)$
\end{tabular}

*Chi-square test was done to measure the level of significance. \#Within parentheses are percentage over column total.

\section{Discussion}

Although it is unlikely that it may directly leads to patients demise, nevertheless, shivering not only causes patients discomfort but also can lead to adverse effect including increased oxygen consumption, lactic acidosis, raised carbon dioxide 'production and increased left ventricular systolic work index ${ }^{7}$. Thus both prevention of shivering and the treatment of established shivering should be regardless clinically relevant medical intervention during the intra-operativeperiod.

Various method are available to control shivering after Sub Arachnid Block. Non pharmacological method using equipment to maintain normothermia are partially effective but may be expensive and are not practical in all the setting. So various drugs have been used to control shivering showing success rate ranging from 30 to $95 \%{ }^{8}$. With the view of serotonin reuptake inhibition like tramadol, ondansetron has important role in shivering control. In a study it has been showed the dose dependent effectiveness of ondansetron to prevent post-anesthetic shivering without affecting core to peripheral redistribution, ofheat during general anesthesia9. In sub arachnoid block, no such study have been performed.

This study demonstrates that there was no signification difference between tramadol (Gr-T), ketamine (Gr-K), ondansetron (Gr-O) group in respect of age, weight and duration of the operation. Core hypothermia was present in all three group. The average tympanic membrane temperature (which denotes core temperature) of $\mathrm{T}, \mathrm{K}$ and $\mathrm{O}$ group was $35.75 \pm 0.91$, $35.83 \pm 0.23,35.78 \pm 1.09$ respectively. This indicates the role of hypothermia in shivering. An important subject has come out from our research. Most patient at first had the highest shivering (excluding recurrence) at the 30 minute, when shivering grade of T, K,O groups were
$1.47 \pm 1.33,1.67 \pm 42$ and $1.80 \pm 1.03$ respectively. This possibly reflects the duration of upward spread of Sub Arachnoid Block as high level of spinal blockade are known to decrease core temperature threshold for shivering ${ }^{9-11}$.

The main goal of the study was to observe the effectiveness of individual drug in the shivering management. Results shows that $\mathrm{T}$ groups is successful in $90 \%$ cases, whereas $\mathrm{K}$ and 0 group lies at $70 \%$ and $66.7 \%$ respectively. The $\mathrm{P}$ value is 0.075 . So, although the difference of effectiveness is not statistically significant but in the parameter of percentage the difference is mentionable. This superiority of tramadol probably indicates that shivering process not only involve serotonin (5HT3) but also involve noradrenalin; not only involve NMDA receptor but also $\mathrm{p}, \mathrm{x}$ receptors have a significant role. So shivering is a complex process, therefore mechanism of its management is also complicated. Moreover, the recurrence rate of T, $\mathrm{K}$ and 0 group was 1,8 and 3 respectively, which is statistically significant $(\mathrm{p}=$ $0.024)$. The highest recurrence in $\mathrm{K}$ group $(26.7 \%)$ is possibly due to short half-life of Ketamine.

With a view to observe complication, it is evident that only $\mathrm{T}$ group has three evidence of nausea or vomiting whereas only $\mathrm{K}$ group has ten incidence of respiratory depression defined as respiratory rate less than eight per minute. Regarding vomiting, there was no significant difference in the incidence of nausea or vomiting between tramadol and other opioids ${ }^{11}$. It has been suggested to inject calculated dose slowly ${ }^{6}$. In a study it has been found tramadol to be superior to pethidine without any incidence of respiratory depression with a success rate of $80.0 \%{ }^{10}$. It acts by inhibiting the reuptake of noradrenalin and serotonin at the nerve terminal. Tramadol and its metabolite non-competitively inhibit the NMDA receptors ${ }^{9,11}$. It has weak opioid effect also.

There are some limitation of this study. In this study, the duration of the surgery was different. Result of few long procedures put a significant impact on the results. This can be prevented in the next by using a non-busy operation theatre and highest monitoring period of all the cases. Onset of action was not recorded here that could give more accuracy. Sample size could be enlarged. The study was conducted at different period of a day. So, there was chance to be affected by circadian fluctuations.Hormonal effect on shivering was not considered in pregnant patients.Oxygen consumption need to be monitored. 


\section{Conclusion}

In the light of discussion of result and analysis, the study concludes that although shivering after Sub Arachnoid Block can be treated by experimental three agents like tramadol, low dose ketamine and ondansetron but for the most benefit of patient, tramadol is better than other two agents. So, use of tramadol can raise a rainbow during the raining of shivering in the horizon of Sub Arachnoid Block anaesthesia.

\section{References}

1. Morgan GE, Mikhail MS, Murray MJ. Patient monitors, Clinical Anaesthesiology, 4th edn, USA, Mc Graw Hill, 2006, pp 147-150 2. Powell RM, Buggy DJ. Ondansetron Given Before Induction of Anaesthesia Reduce shivering after General Anaesthesia, AnesthAnalg 2000; 90: 1423-1427

3. Katzung BG. Opioid analgesic and antagonist, Basic \& Clinical Pharmacology, 9thednMcGrawn Hill, Toronto 2004, pp 497-512

4. Lyons B, Carroll M, McDonald N. A randomised Trial of pethidine, Alfentanil or Doxapram for post Anaesthetic shivering, AnesthAnalg, 1994;78; S-259

5. Miller RD. Temparature monitoring, Anaesthesia 3rd edition Churchill Livingston, New York, 1990, pp 1228-30

6. Mathews S, Mulla A, Varghese P.K, Radim K, Mumtaz S. Post anaesthetic shivering. a new look at tramadol, Anaesthesia 2002;57:387-403

7. Sahin A, Aypur U. Effect of Amino acid solution on intraoperative hypothermia and post-operative shivering. Comparism of two anesthetic regimen, ActaanaetliesfalScand, 2002;46(1):64-7

8. Rein E.B, Filtvedt M, Walloe L, Raeder JC. Hypothermia during laparotomy can be prevented by locally applied warm water and pulsating negative pressure, BJA 2007;98(3):331-6

9. Vaughan DJA, Shinner G, Thornton C, Brunner MD. Effect of tramadol on electroencephalographic and auditory evoked response variables during lightAnaesthesia, BJA, 2000;85(5):705-7

10. Murphy M.T, Lipton J.M, Loughran P, Giesecke AH. Metabolizing and Regulation, Posters, Anasthesiology, 1984;61:3 11. Komatsu R, Sungur MO, Podranski T, Boullian T, hauber R, Rohrbach S, Sessler D. Ondansetron does not reduce the shivering threshold in healthy volunteers, BJA 2006;96(6):732-37 